\title{
The Role of Interphotoreceptor Retinoid-Binding Protein on the Translocation of Visual Retinoids and Function of Cone Photoreceptors
}

\author{
Minghao Jin, ${ }^{1}$ Songhua Li, ${ }^{1}$ Steven Nusinowitz, ${ }^{2}$ Marcia Lloyd, ${ }^{2}$ Jane Hu, ${ }^{2}$ Roxana A. Radu,,${ }^{2}$ Dean Bok, $, 2,3,4$ and \\ Gabriel H. Travis ${ }^{2,5}$

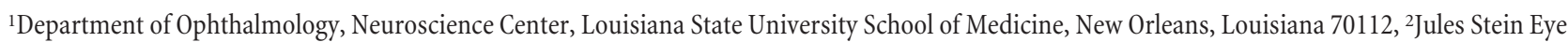 \\ Institute, ${ }^{3}$ Department of Neurobiology, ${ }^{4}$ Brain Research Institute, and ${ }^{5}$ Department of Biological Chemistry, University of California, Los Angeles School of \\ Medicine, Los Angeles, California 90095
}

The first event in light perception is absorption of a photon by the retinaldehyde chromophore of an opsin pigment in a rod or cone photoreceptor cell. This induces isomerization of the chromophore, rendering the bleached pigment insensitive to light. Restoration of light sensitivity requires chemical reisomerization of retinaldehyde via a multistep enzyme pathway, called the visual cycle, in cells of the retinal pigment epithelium (RPE). Interphotoreceptor retinoid-binding protein (IRBP) is present in the extracellular space between photoreceptors and the RPE. IRBP is known to bind visual retinoids. Previous studies on irbp ${ }^{-1-}$ mice suggested that IRBP plays an insignificant role in opsin-pigment regeneration. However, the mice in these studies were uncontrolled for a severe mutation in the rpe65 gene. Rpe65 catalyzes the rate-limiting step in the visual cycle. Here, we examined the phenotype in $i r b p^{-1-}$ mice homozygous for the wild-type (Leu450) rpe65 gene. We show that lack of IRBP causes delayed transfer of newly synthesized chromophore from RPE to photoreceptors. Removal of bleached chromophore from photoreceptors is also delayed in $i r b p^{-1-}$ retinas after light exposure. It was previously shown that rods degenerate in $i r b p^{-/-}$mice. Here, we show that cones and rods degenerate at similar rates. However, cones are more affected functionally and show greater reductions in outer segment length than rods in irbp ${ }^{-1-}$ mice. The disproportionate reductions in cone function and outer-segment length appear to result from mistrafficking of cone opsins due to impaired delivery of retinaldehyde chromophore, which functions as a chaperone for cone opsins but not rhodopsin.

Key words: opsin; pigment epithelium; retinal degeneration; trafficking; visual cycle; vitamin A

\section{Introduction}

Opsin visual pigments are located in a stacked membranous structure of rod and cone photoreceptor cells called the outer segment (OS). Absorption of a photon by a rhodopsin or coneopsin pigment induces isomerization of its retinaldehyde chromophore, activating the receptor. After a brief period, all-transretinaldehyde (all-trans-RAL) dissociates from the bleached pigment, rendering it insensitive to light. Before light-sensitivity can be restored, the all-trans-RAL must be reisomerized to 11-cisretinaldehyde (11-cis-RAL), which recombines with apo-opsin to form a new pigment molecule. Conversion of all-trans-RAL to 11-cis-RAL is performed by a multistep enzyme pathway called

Received Aug. 14, 2008; revised Nov. 21, 2008; accepted Dec. 14, 2008.

This work was supported by grants from the National Eye Institute and the Foundation Fighting Blindness. D.B. is the Dolly Green Professor of Ophthalmology. G.H.T. is the Charles Kenneth Feldman, and Jules and Doris Stein Research to Prevent Blindness Professor. We thank Greg Liou and John M. Nickerson for providing the irbp ${ }^{-/-}$mice. We thank Joanna Kaylor for her help with the analysis of irbp ${ }^{-/-}$mice. We thank John Ramirez, Teresita Yang, and Bryan Chen for their excellent technical assistance. Finally, we thank Nate Roybal for his valuable comments on this manuscript.

Correspondence should be addressed to Gabriel H. Travis, Jules Stein Eye Institute, 100 Stein Plaza, University of California, Los Angeles School of Medicine, Los Angeles, CA 90095. E-mail: travis@jsei.ucla.edu. DOI:10.1523/JNEUROSCI.3882-08.2009

Copyright $\odot 2009$ Society for Neuroscience $\quad$ 0270-6474/09/291486-10\$15.00/0 the visual cycle (see Fig. 1). The first catalytic step of the visual cycle, reduction of all-trans-RAL to all-trans-retinol (all-trans$\mathrm{ROL}$ ), occurs in photoreceptors. The remaining steps occur in cells of the adjacent retinal pigment epithelium (RPE). The location of visual-cycle activities in cells of the RPE requires the translocation of retinoid intermediates across the extracellular space or interphotoreceptor matrix (IPM). Specifically, all-trans-ROL released by photoreceptors must traverse the IPM for uptake by the RPE, while 11-cis-RAL released by RPE cells must traverse the IPM for uptake into photoreceptors (see Fig. 1).

An abundant $140 \mathrm{kDa}$ glycoprotein called interphotoreceptor retinoid-binding protein (IRBP) is present in the IPM (Liou et al., 1982; Hollyfield et al., 1985; Redmond et al., 1985). IRBP was shown in vitro to promote release of 11-cis-RAL from RPE cells (Carlson and Bok, 1992; Edwards and Adler, 2000) and all-transROL from photoreceptors after light exposure (Qtaishat et al., 2005; Wu et al., 2007). These observations suggest that IRBP functions as the carrier protein for 11-cis-RAL and all-trans-ROL during translocation through the IPM (see Fig. 1).

Several years ago, a line of mice was generated with a null mutation in the irbp gene (Liou et al., 1998). Surprisingly, these $\mathrm{irbp}^{-/-}$mice exhibited virtually normal regeneration of rhodopsin after light exposure (Palczewski et al., 1999; Ripps et al., 2000). 


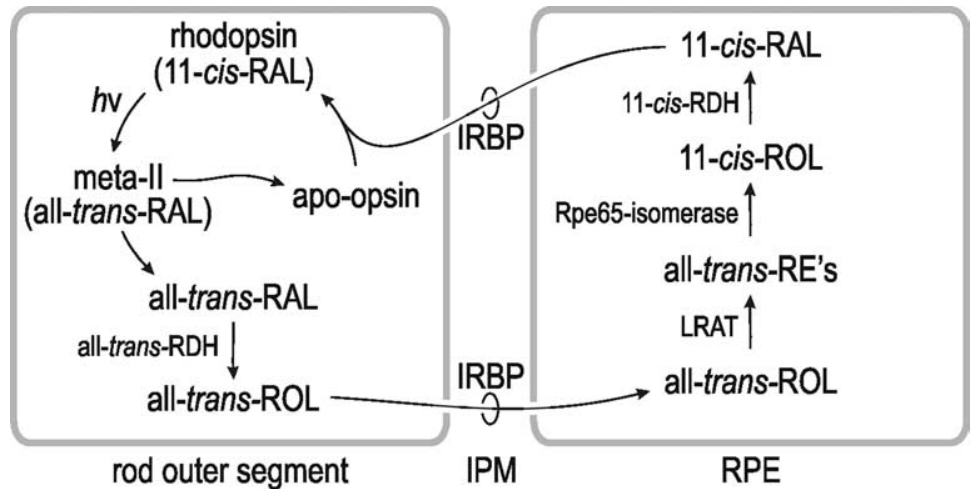

Figure 1. Visual cycle in photoreceptors and RPE cells. Absorption of a photon (hv) by a rhodopsin or cone-opsin pigment molecule induces isomerization of 11-cis-RAL to all-trans-RAL, which subsequently dissociates from the apo-opsin. Free all-transRAL is reduced to all-trans-ROL (vitamin A) by all-trans-RDH. The all-trans-ROL is released into the IPM where it binds IRBP and is subsequently taken up by the RPE. The all-trans-ROL is esterified to a fatty acid by LRAT. The resulting all-trans-RE is hydrolyzed and isomerized to 11-cis-ROL by Rpe65-isomerase. The 11-cis-ROL is oxidized by 11-cis-RDH to 11-cis-RAL. Finally, the 11-cis-RAL is released by the RPE cell into the IPM, where it binds IRBP during translocation to the OS. The 11-cis-RAL recombines with apo-rhodopsin or apo-cone opsin to form a new rhodopsin or cone-opsin pigment molecule.

These observations called into question the assumed importance of IRBP in the translocation of retinoids between photoreceptors and RPE. The $i r b p^{-1-}$ knock-out mouse was generated on a strain 129 background and subsequently crossed onto strain C57BL6 (Liou et al., 1998). It was later shown that C57BL/6 mice carry a spontaneous mutation in the rpe65 gene resulting in a Leu-toMet substitution at codon 450 (Danciger et al., 2000; Wenzel et al., 2001). The previous studies on $i r_{b} p^{-1-}$ mice were uncontrolled for the genotype at rpe65 in both mutants and controls. Retinoid isomerase activity is reduced $\sim 70 \%$ in mice expressing Met450-substituted Rpe65 (Redmond et al., 2007). Mice expressing Met450-substituted Rpe65 exhibit significantly slowed rhodopsin regeneration (Wenzel et al., 2001). Since isomerization is the rate-limiting step in the visual cycle (Mata et al., 2002), the visual-cycle phenotype in $i r b p^{-/-}$mice would be difficult to interpret if isomerase activity were also severely reduced.

In the current study, we moved the $i r b p^{-/-}$mutation onto a $129 /$ Sv background that expresses Leu450 (wild-type) Rpe65. We studied retinoid dynamics in these mice using $\mathrm{rrbp}^{+/+} 129 / \mathrm{Sv}$ mice as controls. After light exposure, we observed abnormal translocation of all-trans-ROL from the retina to the RPE, and abnormal translocation of 11-cis-RAL from RPE to retina in the $i r b p^{-/-}$mice. These mice showed degeneration of rods, as previously reported (Ripps et al., 2000). The $i r b p^{-/-}$mice also showed cone degeneration and a disproportionate reduction in cone function. Cone dysfunction appears to be caused by abnormal trafficking of cone opsins due to impaired delivery of 11-cis-RAL chromophore without IRBP.

\section{Materials and Methods}

Mice and genotyping. Breeder pairs of $i r b p^{-/-}$knock-out mice were generously provided by Greg Liou (Medical College of Georgia, Augusta, GA) and John Nickerson (Emory University, Atlanta, GA). These breeders were all homozygous for the Met450 mutation in the rpe65 gene. We crossed these mice with $129 \mathrm{~S} 2 / \mathrm{Sv}$ mice (Charles River Laboratories), then intercrossed the heterozygous offspring to yield irbp $p^{-1-}$ mice homozygous for the Leu450 allele of rpe65. The genotypes at rpe65 and irbp were determined by PCR and DNA sequencing as described previously (Liou et al., 1998; Palczewski et al., 1999; Radu et al., 2008a). All mice used in the current study were homozygous for the Leu450 allele of $r p e 65$. Except where noted, mice were maintained in $12 \mathrm{~h}$ cyclic light at 30 lux. Dark-reared mice were raised from birth in a ventilated cabinet under total darkness, except for semiweekly exposure to dim red light to change the cages. Where indicated, dark-reared mice were injected intraperitoneally with $1.25 \mu \mathrm{g}$ of 9-cis-retinal (9-cis-RAL) (in 10\% ethanol, $5 \%$ mouse serum albumin and $0.9 \% \mathrm{NaCl}$ ) per gram body weight every $3 \mathrm{~d}$ beginning on postnatal day three (P3). The injection volumes were $50 \mu \mathrm{l}$ during the first week and $100 \mu \mathrm{l}$ thereafter. All experiments on mice were performed according to guidelines established by the University of California, Los Angeles Animal Research Committee and the Association for Research in Vision and Ophthalmology Statement for the Use of Animals in Ophthalmic and Vision Research.

Light and electron microscopy. Mice were anesthetized with an intraperitoneal injection of $15 \mathrm{mg}$ ketamine and $3.0 \mathrm{mg}$ xylazine per gram body weight. After killing, mice were fixed by intracardiac perfusion with a mixture of $2 \%$ paraformaldehyde (PFA) and 2.5\% glutaraldehyde in $0.1 \mathrm{~m}$ sodium phosphate buffer (PB), $\mathrm{pH}$ 7.4. Light cautery was applied at the superior pole of the cornea to mark the orientation before enucleation of the eyeball. A window was cut in the cornea, and the eye was immersed in primary fixative and rotated at room temperature for $2 \mathrm{~h}$. The anterior segment was removed, and the remaining eye cup was refrigerated overnight in primary fixative. The eye cup was trimmed into temporal and nasal hemispheres. All tissues were immersed in $1 \%$ osmium tetroxide in $0.1 \mathrm{M} \mathrm{PB}, \mathrm{pH} 7.2$, for $1 \mathrm{~h}$ followed by dehydration in a graded series of alcohols. The temporal hemispheres were embedded in an Epon/Araldite mixture (5:3 v/v). Light microscope sections were cut at $1 \mu \mathrm{m}$ and stained with $1 \%$ toluidine blue and $1 \%$ sodium borate, then photographed with a light microscope using a $40 \times$ oil-immersion lens (LSM 210; Carl Zeiss Meditec) equipped with a digital camera (Coolsnap; Roper Scientific). All light micrographic images were obtained from temporal-hemisphere sections of the retina at a distance of $200 \mu \mathrm{m}$ inferior to the optic nerve. For electron microscopy, the nasal hemisphere was cut into superior and inferior quadrants and embedded in Araldite 502 (Ted Pella). Ultrathin sections from the inferior nasal quadrant were cut on a Leica Ultracut UCT ultramicrotome. The sections were collected on 200-mesh copper grids and stained with uranium and lead salts before viewing in a Zeiss EM910 electron microscope (Carl Zeiss Meditec).

Expression of IRBP in cultured cells. HEK-293T (293T) cells were grown in DMEM (Invitrogen) supplemented with 10\% heat-inactivated fetal bovine serum and antibiotics ( $100 \mathrm{U}$ per milliliter of penicillin $\mathrm{G}$ and 100 $\mu$ g per milliliter of streptomycin) at $37^{\circ} \mathrm{C}$ in $5 \% \mathrm{CO}_{2}$. We cloned a fulllength cDNA for human IRBP into the pRK5 mammalian expression vector. The pRK5-IRBP and pRK5 control plasmids were transfected into 293T cells using PolyFect reagent (Qiagen) according to the manufacturer's procedure. Two days after transfection, we replaced the culture media with serum-free media and incubated an additional $6 \mathrm{~h}$. Then, we collected the cell-free medium and concentrated it $\sim 20$-fold in an Amicon Ultra 100-KD molecular-weight cutoff (Millipore). We confirmed the presence of human IRBP in this sample by immunoblotting (data not shown).

Retinoid analysis. Overnight dark-adapted mice (5 weeks of age) were anesthetized with intraperitoneal ketamine and xylazine as described above. Pupils were dilated with $1 \%$ (w/v) atropine sulfate in saline solution. The mice were exposed to fluorescent light at 800 lux for $5 \mathrm{~min}$, then transferred to darkness for the indicated times. Mice were killed by cervical dislocation under anesthesia, eyes were enucleated, and the retinas and RPE were separately dissected. All tissue manipulations were done under dim red light (Kodak Wratten 1A). The tissues were homogenized in PBS and the retinoids extracted into hexane as described previously (Radu et al., 2008b). For the ex vivo experiment, we isolated retinas from dark-adapted, 5-week-old wild-type and $\mathrm{rrbp}^{-/-}$mice and placed each in $100 \mu \mathrm{l}$ of conditioned DMEM culture medium plus $20 \mathrm{~mm}$ HEPES buffer, pH 7.2. The wild-type retinal explants were placed in conditioned 
medium from 293T cells expressing human IRBP, while the irbp ${ }^{-/-}$ explants were placed in conditioned medium from $293 \mathrm{~T}$ cells transfected with nonrecombinant $\mathrm{pRK} 5$ plasmid. The retinas were exposed to white light at 800 lux for $5 \mathrm{~min}$, then incubated in the dark for 0,15 , 30, or 60 $\mathrm{min}$. We collected the retinas by centrifugation and homogenized them in 20 mm HEPES, pH 7.2, 0.1\% SDS and 150 mm hydroxylamine. An equal volume of ethanol was added and the retinoids were extracted into hexane for HPLC analysis. Retinoids were analyzed by normal-phase HPLC as described previously (Radu et al., 2008b). In brief, samples were dissolved in $200 \mu \mathrm{l}$ of hexane, and retinoids were separated by chromatography on a silica column (Zorbax-Sil $5 \mu \mathrm{m}, 250 \times 4.6 \mathrm{~mm}$, Agilent Technologies) by gradient elution of mobile phase $(0.2-10 \%$ dioxane in hexane, $2 \mathrm{ml}$ per min flow rate) in an Agilent 1100 liquid chromatograph equipped with a UV photodiode-array detector. Identified peaks were confirmed by spectral analysis and coelution with authentic retinoid standards.

Lipofuscin pigment determination. After killing, eyeballs were collected from 2-month-old wild-type and irbp ${ }^{-/-}$mice as described above. All tissue manipulations were done under dim red light (Kodak Wratten 1A). Eyecups (containing the RPE, choroid, sclera, and retina) were dissected and flash-frozen at $-80^{\circ} \mathrm{C}$. A2E-fluorophores were extracted after homogenizing the eyecup in $1 \mathrm{ml} \mathrm{PBS,} \mathrm{pH} \mathrm{7.2.} \mathrm{Chloroform/methanol} \mathrm{(4}$ $\mathrm{ml} ; 2: 1, \mathrm{v} / \mathrm{v})$ was added, and the samples were extracted with an addi-

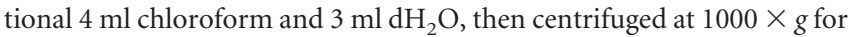
$10 \mathrm{~min}$. The extraction was repeated once with $4 \mathrm{ml}$ chloroform. The organic phases were pooled, dried under a stream of argon gas, and resuspended in isopropyl alcohol. A2E and A2E-precursors were quantitated by normal-phase HPLC on a silica column (Agilent; Zorbax-Sil 5 $\mu \mathrm{m}, 250 \times 4.6 \mathrm{~mm}$ ) in a similar Agilent 1100 liquid chromatograph. The mobile phase (hexane: 2-propanol: ethanol: $25 \mathrm{~mm}$ potassium phosphate: glacial acetic acid, 485:376:100:45:0.275, v/v) was filtered. The flow rate was $1 \mathrm{ml}$ per minute. Column and solvent temperatures were maintained at $40^{\circ} \mathrm{C}$. The identity of A2E was confirmed by spectral analysis and coelution with an authentic standard.

ERG analysis. Five-week-old wild-type and $i r b p^{-/-}$mice were darkadapted overnight and anesthetized with intraperitoneal ketamine and xylazine, as described above. ERGs were recorded from the corneal surface of one eye after pupil dilation with $1 \%(\mathrm{w} / \mathrm{v})$ atropine sulfate in saline solution using a gold-loop electrode referenced to a similar gold wire in the mouth. A needle electrode in the tail served as the ground. All stimuli were presented in a large integrating sphere coated with highly reflective white matte paint (\#6080, Eastman Kodak Corporation) and generated with a photic stimulator (model PS33 Plus; Grass-Telefactor) affixed to the outside of the dome at $90^{\circ}$ to the viewing porthole. Responses were amplified 10,000× (Grass P511 High Performance AC Amplifier) bandpass filtered $(0.1-300 \mathrm{~Hz})$, digitized using an I/O board (PCI-6221, National Instruments) in a personal computer, and averaged. A signal rejection window was used to eliminate electrical artifacts. Rod-mediated responses were obtained with blue flashes (Wratten $47 \mathrm{~A} ; \lambda_{\max }=470 \mathrm{~nm}$ ) varied over an intensity range of $4.0 \mathrm{log}$-units to a maximum intensity of $-0.436 \log \mathrm{cd}-\mathrm{s} / \mathrm{m}^{2}$. Flash intensities were varied in $0.6 \log$-unit steps. Cone-mediated responses were obtained with white flashes up to 0.7 $\mathrm{cd}-\mathrm{s} / \mathrm{m}^{2}$ on a rod-saturating background $\left(32 \mathrm{~cd} / \mathrm{m}^{2}\right)$. All stimuli were presented at $1 \mathrm{~Hz}$ except the brightest flashes, where flash frequency was slowed to $0.2 \mathrm{~Hz}$ to avoid adaptation effects. Signal averaging was done, with up to 30 responses averaged for the dimmest flash intensities.

Immunocytochemistry. Mice were anesthetized with ketamine and xylazine, killed, and fixed by transcardiac perfusion with $4 \%$ PFA in PB, pH 7.2, as described above. Immediately after enucleation, the eyeballs were submerged in $4 \% \mathrm{PFA} / \mathrm{PB}$ on ice, and the corneas and lenses were removed. The resulting eyecups were fixed further in $4 \% \mathrm{PFA} / \mathrm{PB}$ for $3-4 \mathrm{~h}$ at $4{ }^{\circ} \mathrm{C}$ followed by cryoprotection in $30 \%$ sucrose $/ \mathrm{PB}$ and embedding in Optimal Cutting Temperature medium (Sakura Finetechnical). Twelve micrometer sections, cut on a cryostat (Leica; CM3050S), were collected on six serial slides for each eye. Cryosections were incubated with a blocking solution containing DMEM, 10\% fetal calf serum, 2\% goat serum, $2 \%$ donkey serum, and $0.1 \%$ Triton X-100 for $1 \mathrm{~h}$ at room temperature. After removing the blocking solution, sections were incubated with primary antibodies at $4^{\circ} \mathrm{C}$ overnight, and with secondary antibodies at room temperature for $1 \mathrm{~h}$, each followed by four washes with PBS containing $0.1 \%$ Tween 20 detergent. The primary antibodies were the mouse 1D4 monoclonal antibody against a C-terminal peptide of bovine rhodopsin (MacKenzie et al., 1984), and rabbit polyclonal antisera against M-opsin and S-opsin (Millipore Bioscience Research Reagents). The cone sheaths were labeled with fluorescein-tagged peanut agglutinin (PNA) (Vector Laboratories). Propidium iodide (PI) (Invitrogen) was added to the secondary antibody solution to label nuclei. Immunofluorescent signals were captured with an E800 microscope (Nikon) equipped with a digital camera (SPOT II; Diagnostic Instruments). Confocal imaging was done (Leica TCS-SP confocal or upgraded Zeiss LSM 410 microscope; Microcosm) with an argon or helium-neon laser. For each antibody, two or more retinas from different mice were used.

Quantitation of M-cone and S-cone numbers and OS lengths. Retina sections from 5 -week-old wild-type and irbp ${ }^{-1-}$ mice were reacted with antibodies against $\mathrm{M}$-opsin or S-opsin, as described above. We counted $\mathrm{M}$-opsin positive OS along $600 \mu \mathrm{m}$ linear regions in the superior retinas, and S-opsin positive OS along $600 \mu \mathrm{m}$ linear regions in the inferior retinas of wild-type and $i r b p^{-/-}$mice. For the developmental study, retina sections from wild-type and $i r b p^{-/-}$mice at $\mathrm{P} 1$ or $\mathrm{P} 3$ were reacted with antibodies against $\mathrm{M}$-opsin or S-opsin, respectively. We counted $\mathrm{M}$-opsin positive cell bodies along $600 \mu \mathrm{m}$ linear regions in the superior retinas of $\mathrm{P} 1$ wild-type and irbp $\mathrm{p}^{-1-}$ mice and S-opsin positive OS along $600 \mu \mathrm{m}$ linear regions in the inferior retinas of $\mathrm{P} 3$ wild-type and $i r b p^{-1-}$ mice. In all cases, these $600 \mu \mathrm{m}$ linear regions began at the optic nerve head and extended radially toward the superior or inferior peripheral retina. We also measured the OS lengths of $\mathrm{M}$-cone and S-cones in the same regions.

Quantification of M-opsin and S-opsin localization in OS and outer plexiform layer. Retina sections from 3-week-old wild-type and $i r b p^{-/-}$ mice were reacted with antibodies against $\mathrm{M}$-opsin or S-opsin, as above. Fluorescence intensities were measured in the OS and outer plexiform layer (OPL) using the Phoenix v.2 program. We determined the fraction of mislocalized M-opsin and S-opsin according to the following formula: Mislocalization $=\mathrm{OPL} /(\mathrm{OS}+\mathrm{OPL})$.

Quantitative real-time PCR. Total RNA was extracted from the retinas of wild-type and $\mathrm{rrbp}^{-/}$mice using the Absolutely RNA Miniprep kit (Stratagene) with DNase treatment, and was reverse-transcribed to cDNA using SuperScript III (Invitrogen) according to the manufacturer's instructions. Quantitative real-time PCR (qRT-PCR) was performed on a DNA Engine Opticon2 (MJ Research) using a two-step qRT-PCR kit with SYBR Green (Invitrogen) and primer sets specific for M-opsin (5' CTCTGCTACCTCCAAGTGTGG and 5'-AAGTATAGGGTCCCCAGCAGA), S-opsin (5'-TGTACATGGTCAACAATCGGA and 5' -ACACCATCTCCAGAATGCAAG), rhodopsin (5'-CAAGAATCCACTGGGAGATGA and 5'-GTGTGTGGGGACAGGAGACT), and $18 \mathrm{~S}$ rRNA (5'TTTGTTGGTTTTCGGAACTGA and 5'-CGTTTATGGTCGGAACTACGA). Fluorescence data were analyzed with Opticon 2 software. Three mice of each genotype were analyzed and all samples were run in duplicates. Starting templates were normalized after determining $18 \mathrm{~S}$ rRNA Ct-values for each sample. Relative opsin mRNA levels were determined from the $\Delta C t$ values.

Immunoblot analysis. Retina and RPE homogenates were prepared as above. Protein concentrations in the homogenates were determined with the micro BCA protein assay kit (Pierce). After incubating the homogenates for $10 \mathrm{~min}$ at $75^{\circ} \mathrm{C}$ in Laemmli buffer, samples containing the indicated amounts of total protein were separated by SDS-PAGE in a 10 or $12 \%$ polyacrylamide gel, then transferred to an Immobilon-P membrane (Millipore) by electrophoresis in a semidry transfer apparatus (Bio-Rad). The membrane was incubated in blocking buffer for $2 \mathrm{~h}$ at $37^{\circ} \mathrm{C}$, then overnight at $4^{\circ} \mathrm{C}$, with either the primary antibodies described above (see Immunocytochemistry) or a rabbit polyclonal antibody against Rpe65 (Mata et al., 2004). After washing three times in PBS for $10 \mathrm{~min}$, the membrane was incubated with horseradish peroxidase-conjugated goat anti-mouse or rabbit IgG (Jackson ImmunoResearch Laboratories) for $1 \mathrm{~h}$ and washed again. Opsins and Rpe65 that reacted with the antibodies were visualized with the Enhanced Chemiluminescence-Plus Western blot detection system (Amersham Biosciences). 


\section{A. Light microscopy}

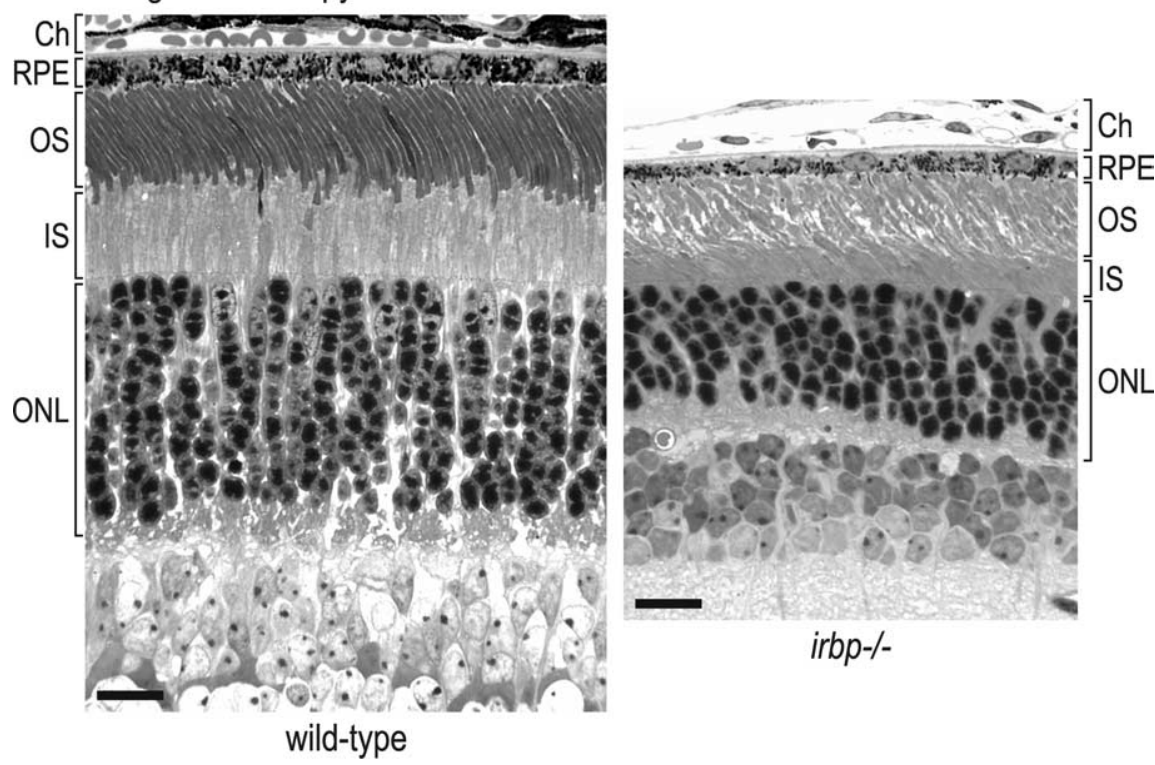

B. Electron microscopy

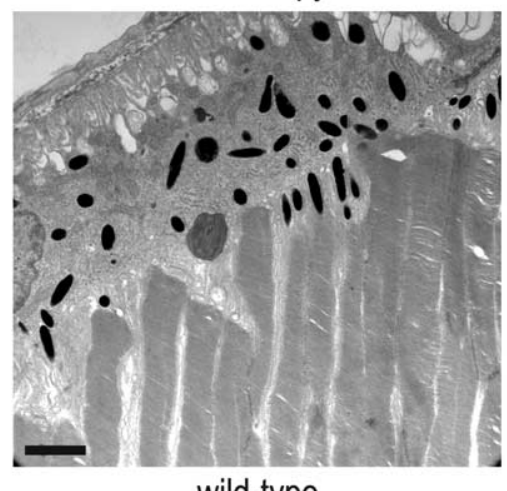

wild-type

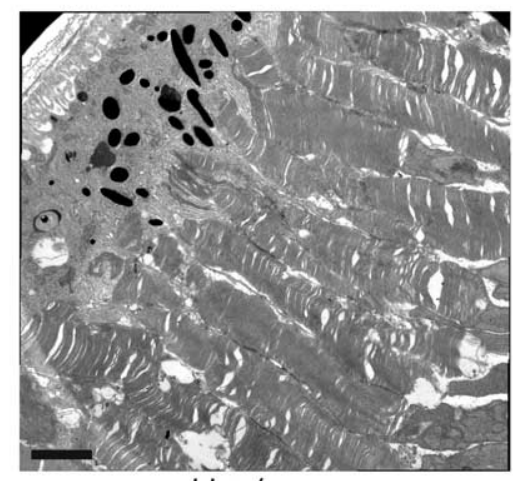

irbp-/-

returned the mice to darkness. At different times, we killed the mice, collected eyes, dissected the retinas and RPE separately, and determined the content of retinoids in each tissue by HPLC. Since the retinas of $\mathrm{irbp}^{-1-}$ mice are partially degenerate (Fig. $2 A$ ), we expressed the levels of each retinoid as the percentage of total retinoids in wild-type or irbp ${ }^{-1-}$ eyes. Levels of 11-cisRAL were similar in dark-adapted wildtype and $\mathrm{rrbp}^{-/-}$retinas (Fig. 3A). Light exposure converted similar fractions of 11-cis-RAL to all-trans-RAL in wild-type and $\mathrm{rrbp}^{-1-}$ mice (Fig. $3 B$ ). However, recovery of 11-cis-RAL after the photobleach was delayed in $\mathrm{irbp}^{-/-}$versus wild-type retinas (Fig. 3A). In contrast, 11-cis-RAL was higher in the RPE of $i r b p^{-/-}$versus wild-type mice during the postbleach recovery period (Fig. 3D). Levels of all-transROL were elevated in the retinas of $i r b p^{-/-}$ mice during postbleach recovery (Fig. 3C). After uptake into RPE cells, all-trans-ROL is rapidly esterified by lecithin:retinol acyltransferase (LRAT) to yield all-transretinyl esters (all-trans-REs) (Fig. 1). Levels of all-trans-REs were lower in irbp ${ }^{-/-}$ versus wild-type RPE during the postbleach period. Since retinyl esters are present in RPE but not mouse retinas (Mata et al., 2002), the relative amount of all-trans-REs in retina versus RPE provides an estimate of RPE contamination in a retina sample. Retinas from wild-type and $i r b p^{-/-}$mice contained $\sim 3 \%$ of the all-trans-REs in the corresponding RPE samples (data not shown). Therefore, our retina samples contained $\sim 3 \%$ RPE contamination. Together, these observations show that the transfer of newly synthesized 11-cis-RAL from the RPE to the retina, and of all-trans-ROL from bleached photore-

Figure 2. Histologic analysis of wild-type and $\mathrm{rrbp}^{-/-}$retinas from 5 -week-old mice. $\boldsymbol{A}$, Light microscopic analysis of retina sections. The choroid (Ch), RPE, OS, inner segment (IS), and outer-nuclear layers (ONL) are shown. Scale bars, $20 \mu \mathrm{m}$. $\boldsymbol{B}$, Electron microscopy of OS and RPE. Scale bars, $2.0 \mu \mathrm{m}$. Note the disorganization of OS in the $i r b p^{-1-}$ retina. Also note the reduced length,increased diameter, and irregularity of $0 S$ and the reduced number of nuclei in the $0 \mathrm{NL}$ of the irbp ${ }^{-1-}$ retina.

\section{Results}

Photoreceptors degenerate in irbp ${ }^{-/-}$mice

We analyzed retina sections from 5 -week-old wild-type and irbp ${ }^{-/-}$mice by light microscopy. Figure $2 \mathrm{~A}$ shows representative sections from the inferior-temporal retina. The outernuclear layers of $\mathrm{irbp}^{-/-}$retinas were reduced in thickness to 7-8 nuclei versus $10-11$ nuclei in wild-type mice, indicating approximately one-third loss of photoreceptors. This degree of degeneration agrees with published light microscopic data for $i r b p^{-/-}$ mice (Ripps et al., 2000). The OS layer appeared slightly thinner in $i r b p^{-1-}$ retinas by light microscopy (Fig. $2 A$ ). Electron microscopy of the distal retina and RPE showed mild disorganization of rod OS, shortening of OS and inner segments, and increased rod OS diameters (Fig. 2B).

\section{Retinoid dynamics in irbp ${ }^{-/-}$mice}

If IRBP functions to translocate all-trans-ROL and 11-cis-RAL across the IPM, levels of the visual retinoids should be different in the retina and RPE of $i r b p^{-/-}$versus wild-type mice after light exposure. To test this possibility, we exposed dark-adapted wildtype and $i r b p^{-1}$ mice to bright light (800 lux) for $5 \mathrm{~min}$, then ceptors to the RPE, is impaired in $i r b p^{-/-}$mice.

To explore further the role of IRBP in the extraction of all-trans-ROL from bleached photoreceptors, we isolated retinas from dark-adapted wild-type and $i r b p^{-1-}$ mice. We placed the wild-type retinas in buffer containing medium from HEK-293T cells expressing human IRBP as a source of exogenous IRBP. We placed the irbp $p^{-1}$ retinas in buffer containing medium from HEK-293T cells transfected with nonrecombinant pRK5 plasmid. Both groups of retina explants were exposed to light at 800 lux for $5 \mathrm{~min}$, then transferred to darkness for different times. Finally, we removed the buffer and extracted retinoids from retina explant homogenates for HPLC analysis. Retinas from $i r b p^{-1-}$ mice, in media lacking both endogenous and exogenous IRBP, showed elevated alltrans-RAL and all-trans-ROL compared with wild-type retinas in media containing IRBP (Fig. $3 G, H$ ). These results agree with results from the in vivo study (Fig. $3 B, C$ ) and provide further evidence that IRBP functions to extract all-trans-ROL from bleached photoreceptors.

Elevated all-trans-RAL in the retina is associated with accumulation of lipofuscin pigments in the RPE of two mouse models 

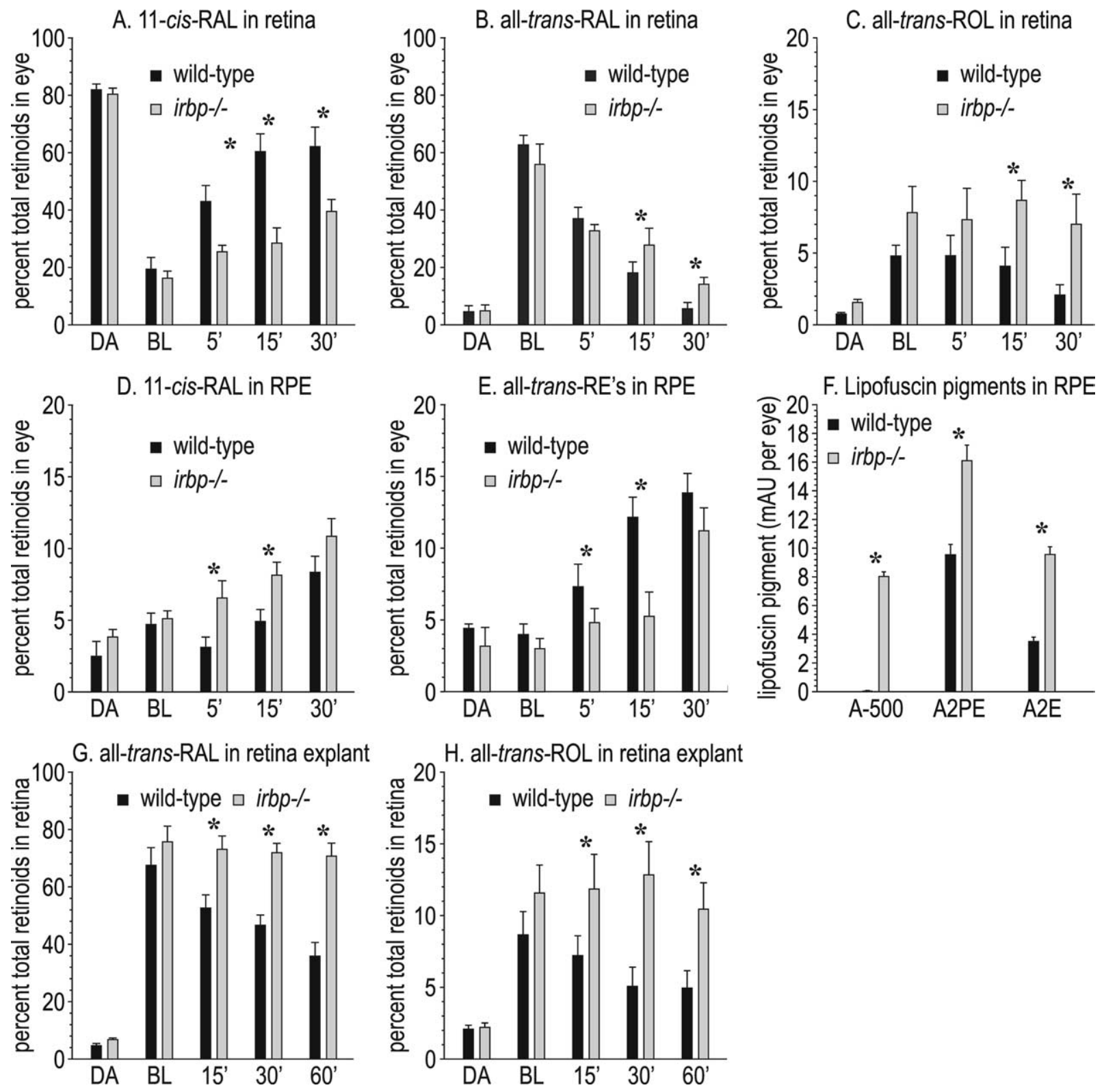

Figure 3. Retinoid dynamics in retina and RPE from wild-type and irbp ${ }^{-/-}$mice. $\boldsymbol{A}, 11$-cis-RAL levels in retinas from mice under the lighting conditions: overnight dark-adapted (DA), immediately postbleach (BL), and at the indicated times in minutes after return to darkness. $\boldsymbol{B}$, All-trans-RAL levels in retinas. $\boldsymbol{C}$, All-trans-ROL levels in retinas. $\boldsymbol{D}$, 11-cis-RAL levels in RPE. $\boldsymbol{E}$, All-trans-RE levels in RPE. Retinoids are expressed as a percentage of total retinoids per eye. Note the lower 11-cis-RAL, higher all-trans-RAL, and higher all-trans-ROL levels in irbp ${ }^{-/-}$retinas during postbleach recovery in darkness. Also note the higher 11-cis-RAL and lower all-trans-RE levels in irbp ${ }^{-1-}$ RPE during postbleach recovery. $F$, Lipofuscin pigments, A-500, A2PE and A2E in wild-type and $\mathrm{irbp}^{-/-R P E}$. Expressed at milli-absorbance units (mAU) per eye. G, Levels of all-trans-RAL in wild-type (WT) and irbp ${ }^{-/-}$retina explants. $\boldsymbol{H}$, Levels of all-trans-ROL in WT and irbp $p^{-/-}$retina explants. Retinoids are expressed as a percentage of total retinoids per retina explant. Note the higher all-trans-RAL and all-trans-ROL in irbp ${ }^{-/-}$explants during postbleach recovery. Asterisks indicate statistically significant differences between wild-type and irbp ${ }^{-/-}(p \leq 0.05)$. Error bars indicate SDs $(n=4)$.

for inherited retinal and macular degeneration (Weng et al., 1999; Maeda et al., 2005). Accordingly, we measured levels of A2E and related lipofusin pigments in irbp ${ }^{-/-}$mice. The A-500 pigment (Mata et al., 2000; Radu et al., 2008b) was virtually undetectable in wild-type and abundantly present in irbp ${ }^{-1-}$ RPE (Fig. $3 F)$. The lipofuscin fluorophores, $\mathrm{A} 2 \mathrm{PE}$ and $\mathrm{A} 2 \mathrm{E}$ were 1.7- and 2.7-fold increased, respectively, in $i r b p^{-1-}$ mice (Fig. $3 F$ ). These data corroborate the dependence of lipofuscin formation on elevated all-trans-RAL in the retina.

Electroretinographic responses of wild-type and $i r b p^{-/-}$mice The electrical response of the retina to a light flash can be measured from the corneal surface of live animals as an electroretinogram
(ERG). We performed ERG analysis on 5-week-old wild-type and irb $p^{-1-}$ mice raised under cyclic light and dark-adapted overnight before the study. Dim flashes (down 2.2 log-units from the maximal flash intensity) were used to elicit rod responses. Representative tracings are shown in Figure $4 A$, and the flash-intensity response curves in Figure 4C. Rod-isolated response amplitudes were decreased $\sim 25 \%$ (Fig. $4 C$ ), consistent with the loss of $\sim 30 \%$ of photoreceptors by histologic analysis (Fig. $2 A$ ). We also elicited cone responses by exposing mice to a rod-saturating background light and stimulating with bright achromatic flashes. Unexpectedly, the cone response was reduced $\sim 50 \%$ in $\mathrm{irbp}^{-1-}$ mice at higher flash intensities (Fig. $4 B, D$ ). This result shows that cones are more affected functionally than rods in $i r b p^{-/-}$mice. 

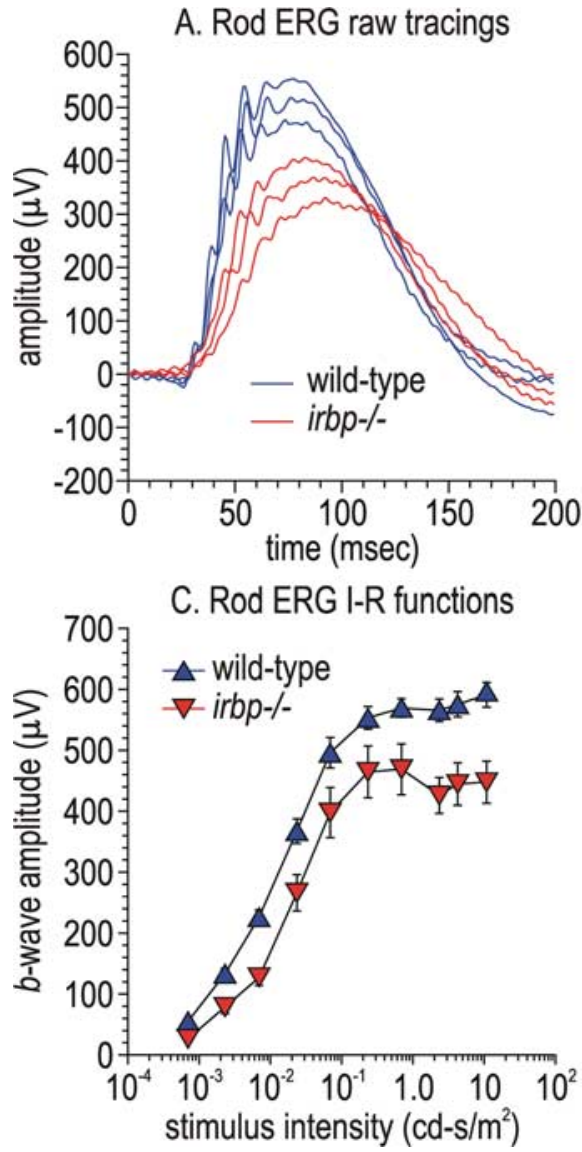

\section{B. Cone ERG raw tracings}
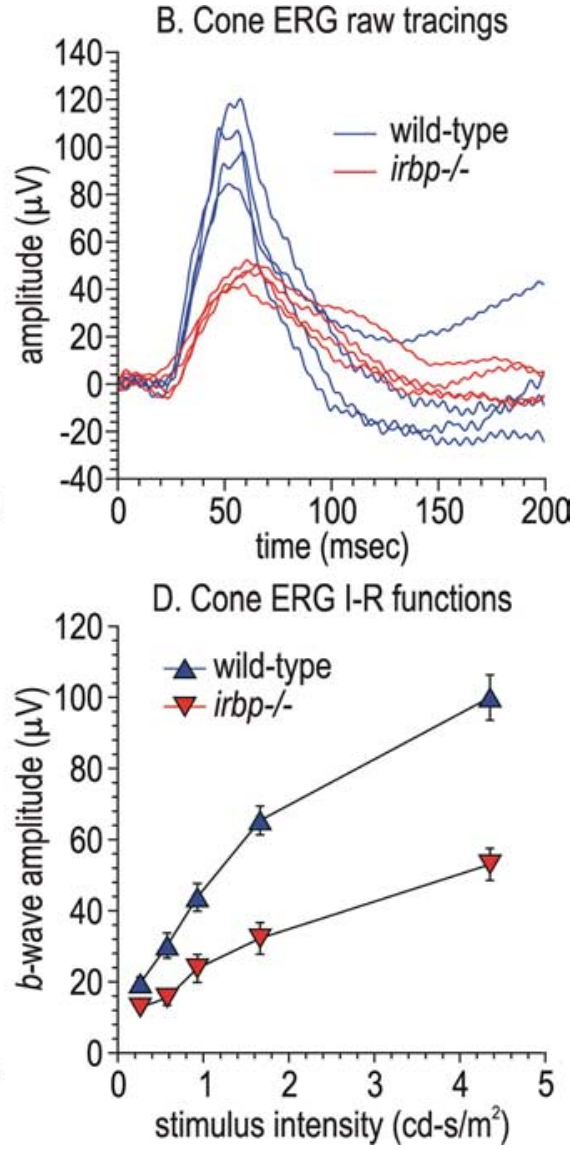

Figure 4. Electroretinography of wild-type and $i r b p^{-1-}$ mice. $\boldsymbol{A}$, Representative raw ERG tracings of rod responses in three wild-type and $i r b p^{-1-}$ mice using stimulus-flash intensities of $-2.64 \log \mathrm{cd}-\mathrm{s} / \mathrm{m}^{2}$. $\boldsymbol{B}$, Representative raw ERG tracings of cone responses in four wild-type and irbp ${ }^{-1-}$ mice. Data were acquired using stimulus-flash intensities of $0.70 \mathrm{~cd}-\mathrm{s} / \mathrm{m}^{2}$ with a rod-saturating background light. $\boldsymbol{C}$, Rod $b$-wave intensity-response functions in wild-type and irbp ${ }^{-/-}$mice. $\boldsymbol{D}$, Cone $b$-wave intensity-response functions in wild-type and $i r b p^{-/-}$mice.

Distribution of cone opsins in wild-type and $i r b p^{-/-}$mice

To understand the cause of the reduced cone ERG responses, we performed immunocytochemistry on retina sections from wildtype and $i r b p^{-/-}$mice using antisera to the middle- and shortwavelength cone opsins (M-opsin and S-opsin) (Fig. 5A,B). We also labeled wild-type and $i r b p^{-/-}$retina sections with fluorescein-tagged PNA. This lectin binds to glycoconjugates in the cone, but not rod matrix-sheaths (Johnson and Hageman, 1987). The number of cone OS labeled with antisera against $\mathrm{M}$-opsin and S-opsin were reduced 1.5-fold and 1.4-fold, respectively in $i r b p^{-/-}$versus wild-type retinas (Fig. $5 C$ ). Furthermore, $\mathrm{M}$-cone and S-cone OS were both $\sim 2.2$-fold shorter in irbp $\mathrm{p}^{-/-}$ versus wild-type retinas (Fig. 5D).

\section{Mislocalization of cone opsins in $i r b p^{-/-}$retinas}

Unlike rhodopsin, cone opsins require 11-cis-RAL chromophore as a chaperone for their normal trafficking to the OS (Rohrer et al., 2005; Zhang et al., 2008). Since delivery of 11-cis-RAL to the retina is impaired in $i r b p^{-1-}$ mice (Fig. $3 A, D$ ), it seemed possible that cone opsins are mislocalized in $i r b p^{-1-}$ retinas. To test this possibility, we did immunocytochemistry on retina sections from 3-week-old mice using antisera against M-opsin. M-opsin immunoreactivity was largely confined to the cone OS in wild-type retinas, although a small amount of immunoreactivity was also present in cone cell-bodies and synaptic termini (Fig. 6A), as previously reported in wild-type mice and cattle (Mavlyutov et al., 2002; Jimeno et al., 2006). In irbp ${ }^{-/-}$ mice, a much greater fraction of M-opsin immunoreactivity was present in the cell bodies and synaptic termini of cones (Fig. $6 B$ ). If this $\mathrm{M}$-opsin mislocalization results from impaired delivery of 11-cis-RAL chromophore to cones, administration of excess exogenous chromophore should compensate for the lack of IRBP and correct the trafficking defect. We administered 9-cis-RAL to 3-d-old irbp $p^{-/-}$mice for 3 weeks. This treatment corrected M-opsin mislocalization in $i r b p^{-1-}$ mice (Fig. 6C). This experiment was repeated testing for S-opsin mislocalization, with similar results (immunofluorescent data not shown). By measuring fluorescence intensity in the OS and OPL, we estimated the fraction of M-opsin and S-opsin mislocalization in wild-type mice, $i r b p^{-1-}$ mice, and irbp ${ }^{-/-}$mice treated with 9-cisRAL (Fig. 6E). The fractional mislocalization of both cone opsins were restored to approximately wild-type values in $i r b p^{-/-}$ mice after administration of 9-cis-RAL.

\section{Loss of IRBP does not affect formation of cone cells}

Since the onset of cone formation and IRBP expression both occur at embryonic days 10-11 in the developing mouse retina (Carter-Dawson et al., 1986; Liou et al., 1994), IRBP may play a role in the formation of cones. Accordingly, cone loss in $i r b p^{-/-}$mice (Fig. 5) may represent a developmental rather than a degenerative process. To test this possibility, we performed immunocytochemistry on $\mathrm{P} 1$ and $\mathrm{P} 3$ mouse retinas using antisera against $\mathrm{M}$-opsin and $\mathrm{S}$-opsin (Fig. $7 A, B$ ). The numbers of cones detected by these antibodies were similar in wild-type and $i r b p^{-/-}$retinas (Fig. $7 C$ ). Thus, cone loss in $i r b p^{-/-}$mice is not the result of a developmental defect.

\section{Opsin mRNA and protein levels in wild-type and $\operatorname{irb} p^{-1-}$ mice}

We measured opsin mRNA levels in cyclic-light and dark reared wild-type and $i r b p^{-1-}$ mice by qRT-PCR. Rhodopsin mRNA levels were reduced $\sim 30 \%$ in cyclic-light-reared wild-type versus $\mathrm{irbp}^{-/-}$mice (Fig. 8A). M-opsin and S-opsin mRNA levels were reduced $\sim 50$ and $40 \%$, respectively (Fig. $8 A$ ). Levels of the rhodopsin and cone-opsin $m$ RNAs did not change with dark-rearing in wild-type mice. However, we observed significantly reduced $\mathrm{S}$-opsin mRNA levels in dark- versus cyclic-light-reared $i r b p^{-1-}$ mice (Fig. $8 \mathrm{~A}$ ). We also did immunoblot analysis of rhodopsin and the cone opsins to estimate protein levels in cyclic-lightreared wild-type and $i r b p^{-/-}$mice. The levels of M-opsin and $\mathrm{S}$-opsin immunoreactivity were roughly equivalent in $30 \mu \mathrm{g}$ of $\mathrm{irbp}^{-/-}$and $7.5 \mu \mathrm{g}$ of wild-type retina homogenates (Fig. $8 \mathrm{~B}$ ). In contrast, rhodopsin immunoreactivity was decreased $\sim 25 \%$ in $\mathrm{irbp}^{-/-}$versus wild-type retina homogenates containing $0.5 \mu \mathrm{g}$ total protein (Fig. $8 \mathrm{~B}$ ). As expected, levels of the Rpe65 were similar in RPE homogenates from wild-type and $i r b p^{-/-}$mice (Fig. $8 B$ ). 

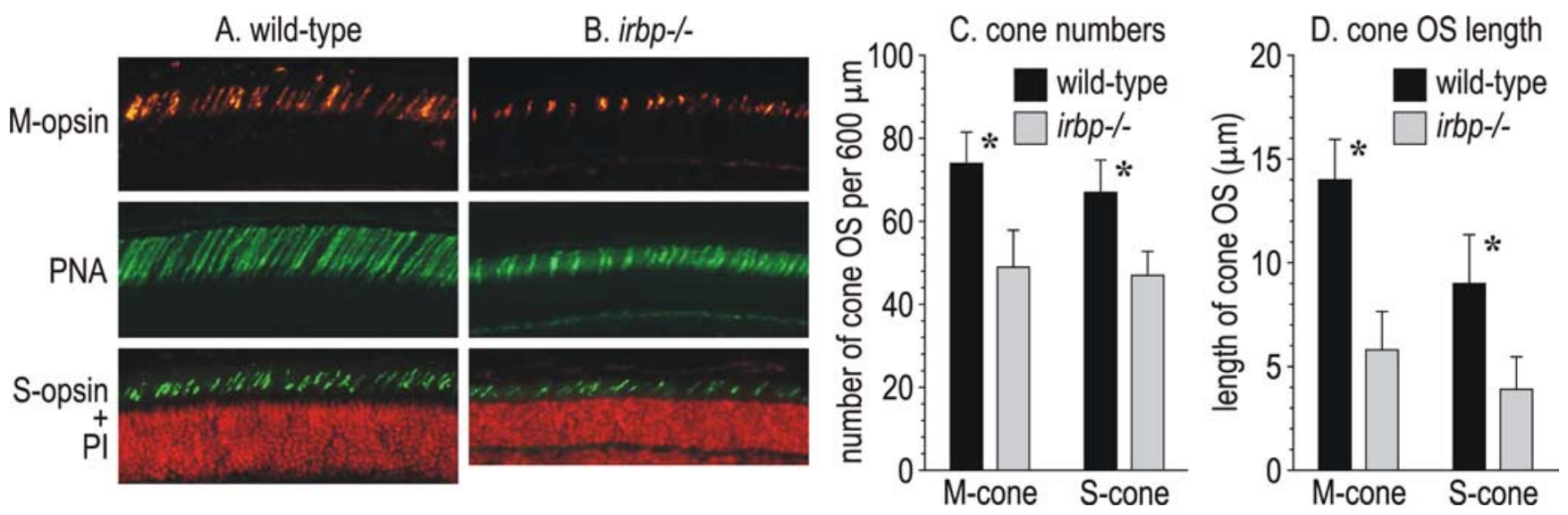

Figure 5. Reduced cone numbers and cone-0S lengths in irb ${ }^{-/-}$versus wild-type retinas. $A$, Immunocytochemistry showing M-opsin immunoreactivity (top), labeling with fluorescein-tagged PNA (middle), and S-opsin immunoreactivity plus PI staining of nuclei (bottom) in a wild-type mouse retina. $B$, Similar labeling in an irbp ${ }^{-1-}$ mouse retina. $C$, Histograms showing numbers of $\mathrm{M}$-cones and $\mathrm{S}$-cones per $600-\mu \mathrm{m}$-width sections of retina from wild-type and irbp ${ }^{-/-}$mice. $\boldsymbol{D}$, Histograms showing average lengths of $\mathrm{M}$-cone and S-cone $0 \mathrm{~S}$ in wild-type and irbp ${ }^{-/-}$mice. Asterisks indicate statistically significant differences between wild-type and irbp ${ }^{-1-}(p \leq 0.05)$. Error bars indicate SDs $(n=4)$.

Accelerated cone dysfunction in darkreared $\operatorname{irbp}^{-/-}$mice

The results presented above suggest that cone dysfunction in $i r b p^{-/-}$mice may be mediated by impaired delivery of 11-cisRAL to cones. Alternatively, cone dysfunction may result from delayed removal of all-trans-ROL or the resulting increased all-trans-RAL in $i r b p^{-/}$photoreceptors after light exposure (Fig. $3 B, C, G, H$ ). To distinguish between these potential causes, we raised wild-type and $\mathrm{rrbp}^{-/-}$mice under total darkness and measured cone $b$-wave responses. Surprisingly, the cone $b$-wave response was significantly reduced in dark- versus cyclic-light-reared irbp $p^{-/-}$ mice (Fig. 9A). In contrast, the cone $b$-wave response was unchanged in darkversus cyclic-light-reared wild-type mice (Fig. 9). Consistently, the M-opsin and S-opsin mRNA levels were lower, while the rhodopsin mRNA was unchanged, in dark- versus cyclic-light-reared $\operatorname{irbp}^{-/-}$ mice (Fig. 8A). Dark rearing had no effect on rhodopsin, M-opsin, or S-opsin mRNA levels in wild-type mice (Fig. $8 A$ ). Thus, dark-rearing had a deleterious effect on cone but not rod function, and only in irbp ${ }^{-/-}$mice. In contrast, treatment with 9-cis-RAL partially corrected the reduced cone $b$-wave response in cyclic light-reared irbp ${ }^{-/-}$mice (Fig. 9B).

\section{Discussion}

In the current study, we re-examined the $i r b p^{-/-}$phenotype in mice homozygous for the normal (Leu450) allele of rpe65. Compared with wild-type mice (also Leu450 at rpe65), irbp ${ }^{-1-}$ mice showed slower recovery of 11-cis-RAL levels in the retina after a photobleach (Fig. 3A). This was balanced by higher 11-cis-RAL in the RPE (Fig. 3D). We also observed higher levels of all-transROL in irbp ${ }^{-/-}$retinas (Fig. 3C,H), and lower levels of all-transREs in irbp ${ }^{-1-}$ RPE (Fig. 3E) after a photobleach. These data corroborate the previous in vitro observations that IRBP promotes the release of 11-cis-RAL from RPE cells (Carlson and Bok,
A. wild type

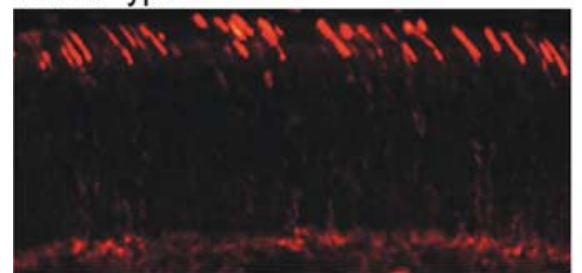

C. irbp-/- +9-cis-RAL

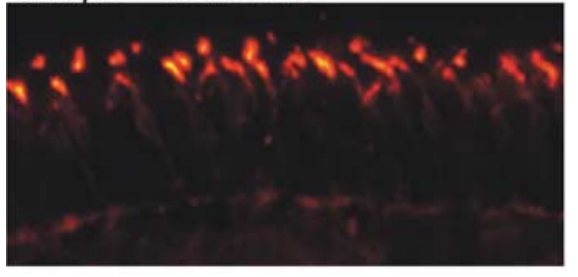

B. irbp-/-

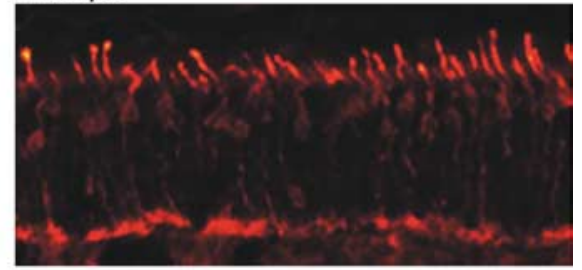

D. DIC

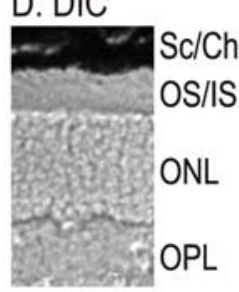

E. opsin in OPL

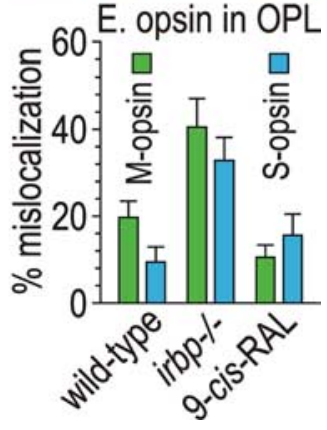

Figure 6. Immunocytochemistry showing mislocalization of $\mathrm{M}$-opsin in irbp $p^{-/-}$photoreceptors. $\boldsymbol{A}, \mathrm{M}$-opsin immunoreactivty in a section of distal retina from a wild-type mouse. $B, M$-opsin immunoreactivity in a distal retina section from an irbp ${ }^{-1-}$

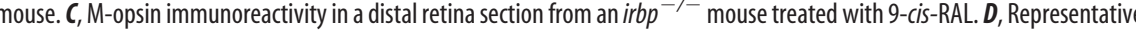
differential interference contrast (DIC) image of a similar retina section from an irbp ${ }^{-1-}$ mouse showing cell layers: sclera and percentage-mislocalization derived by dividing OPL immunofluorescence by the sum of OPL and OS immunofluorescence. Note the restoration of $\mathrm{M}$-opsin and S-opsin mislocalization in irbp ${ }^{-1-}$ mice after administering 9-cis-RAL.

1992; Edwards and Adler, 2000) and all-trans-ROL from bleached photoreceptors (Qtaishat et al., 2005; Wu et al., 2007). Since the reaction catalyzed by all-trans- $\mathrm{RDH}$ is reversible, increased all-trans-ROL causes increased all-trans-RAL, as observed in bleached $\mathrm{irbp}^{-/-}$retinas (Figs. $3 B, G$ ).

Approximately $30 \%$ of photoreceptors had degenerated by 5 weeks in $\mathrm{irbp}^{-/-}$mice (Fig. $2 A$ ), consistent with previous observations (Ripps et al., 2000). The remaining photoreceptors showed mild shortening, cell hypertrophy, and disorganization of OS (Fig. $2 B$ ). The rod ERG response was decreased $\sim 25 \%$ in 5-week-old $\mathrm{irbp}^{-1-}$ mice (Fig. 4C), similar to the extent of rod degeneration by light microscopy. Unexpectedly, the cone ERGresponse was decreased $\sim 50 \%$ in the same mice (Fig. $4 D$ ). The mouse retina contains $97 \%$ rods (Carter-Dawson and LaVail, 1979), hence cone numbers are difficult to quantify by simple 

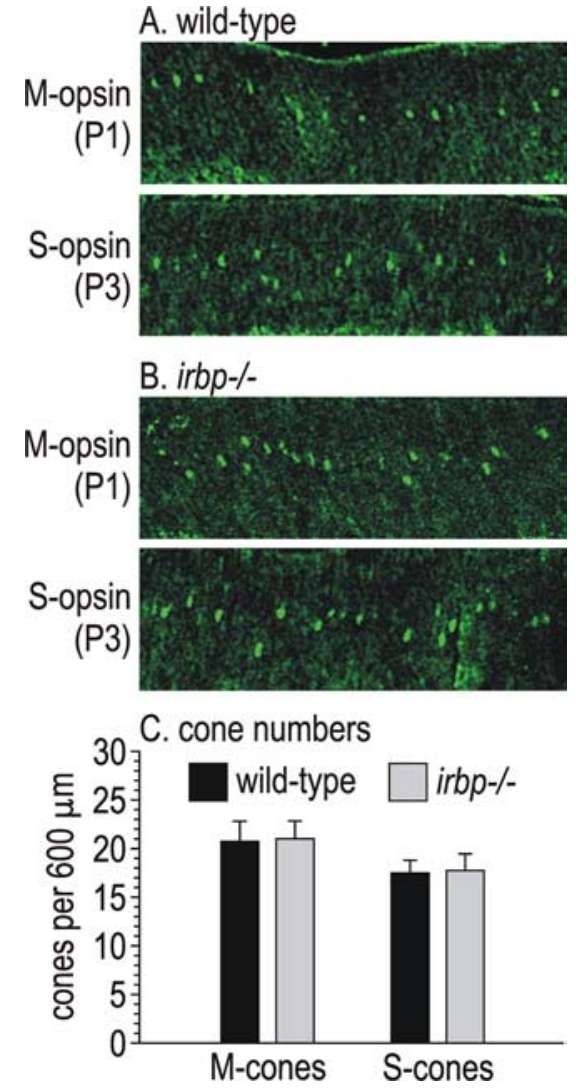

Figure 7. Immunocytochemistry showing $\mathrm{M}$ - and $\mathrm{S}$-opsin in $\mathrm{P} 1$ and $\mathrm{P} 3$ mouse retinas. $\boldsymbol{A}$, Retina sections from wild-type mice showing M-opsin immunoreactivity in cone cell-bodies at P1 (top) and S-opsin in cone cell-bodies at P3 (bottom). $\boldsymbol{B}$, Retina sections from irbp ${ }^{-/-}$mice at the same ages showing M-opsin and S-opsin immunoreactivity in cone cell-bodies. $\mathbf{C}$, Histograms showing numbers of $\mathrm{M}$-cones and $\mathrm{S}$-cones per $600-\mu \mathrm{m}$-width section of retina from wild-type and $\mathrm{irbp}^{-1-}$ mice at P1 or P3. Error bars indicate SDs $(n=4)$.

histologic analysis. To estimate the extent of cone degeneration, we performed immunocytochemistry using antisera against the mouse cone pigments, $\mathrm{M}$-opsin and S-opsin. The number of $\mathrm{M}$-cones and S-cones were reduced 1.5-fold and 1.4-fold, respectively (Fig. $5 C$ ), similar to the extent of rod degeneration by histological analysis (Fig. 2A). The reduction in cone numbers was not due to a developmental defect, since the number of $\mathrm{M}$-opsin and S-opsin expressing cones were similar in wild-type and $i r b p^{-1-}$ retinas at $\mathrm{P} 1$ and $\mathrm{P} 3$ (Fig. $7 C$ ). Hence, the greater reduction in cone versus rod function by ERG analysis cannot be explained by faster degeneration of cones.

We observed partial mislocalization of M-opsin to the cell bodies and synaptic termini of cones in irbp $p^{-/-}$mice (Fig. $6 \mathrm{~B}$ ). A possible explanation for this mislocalization is impaired delivery of 11-cis-RAL to cones, since cone opsins, but not rhodopsin, require visual chromophore as a chaperone for correct trafficking to the OS (Rohrer et al., 2005; Zhang et al., 2008). Consistent with this explanation, cone OS were 2.2 -fold shorter in $i r b p^{-/-}$versus wild-type retinas (Fig. 5D), suggesting impaired delivery of cone opsins to the OS. To test this explanation, we treated $\mathrm{rrbp}^{-1-}$ mice with exogenous 9-cis-RAL, which combines with apo-opsins to form functional pigments (Pepperberg et al., 1978). Parenteral administration of 9-cis-RAL at similar doses was shown to yield high levels of this chromophore in mouse retinas (Van Hooser et al., 2002). The presence of excess 9-cis-RAL chromophore rescued the mislocalization of M-opsin and S-opsin in irbp ${ }^{-/-}$mice (Fig. 6 E). In fact, M-opsin mislocalization in cone cell bodies and synaptic termini appeared lower in 9-cis-RAL-treated irbp $p^{-/-}$ versus untreated wild-type retinas (Fig. 6A, C). We also observed partial rescue of the cone ERG phenotype in $i r b p^{-1-}$ mice after treatment with 9-cis-RAL (Fig. 9B). These results suggest that cone dysfunction in irbp ${ }^{-/-}$mice results from impaired delivery of visual chromophore and subsequent abnormal trafficking of cone opsins.

Another possible cause of rod and cone degeneration in $\mathrm{irbp}^{-/-}$mice is toxicity from the elevated all-trans-ROL and alltrans-RAL after light exposure (Fig. $3 B, C, G, H$ ). The deleterious effects of elevated all-trans-RAL may be indirect through its condensation with phosphatidylethanolamine to form toxic lipofuscin pigments such as A2E (Sakai et al., 1996; Reinboth et al., 1997). A2E has been shown to be toxic in numerous studies, as reviewed (Travis et al., 2007). A2E and the related pigments, A-500 and A2PE are elevated in irbp ${ }^{-/-}$RPE (Fig. $3 F$ ). We tested the hypothesis that delayed removal of all-trans-ROL from bleached photoreceptors is responsible for photoreceptor degeneration by raising irbp ${ }^{-1-}$ mice in total darkness. Photoisomerization does not occur in the dark, hence all-trans-ROL and alltrans-RAL are constitutively low in retinas of dark-reared mice. Dark-rearing also strongly inhibits formation of the lipofuscin fluorophore, A2E (Mata et al., 2000). Instead of the anticipated protective effect, cone function was significantly reduced in $i r b p^{-/-}$mice raised under total darkness (Fig. 9). The M-opsin and S-opsin mRNA's were also reduced in dark- versus cycliclight-reared $\mathrm{irbp}^{-/-}$mice (Fig. $8 \mathrm{~A}$ ). Dark rearing did not affect rhodopsin mRNA levels in irbp ${ }^{-/-}$mice, however. Also, darkrearing did not affect cone function in wild-type mice (Fig. 9), and we observed no effect of dark-rearing on rod- or cone-opsin mRNA levels in wild-type mice (Fig. $8 A$ ). Therefore, elevated all-trans-ROL, all-trans-RAL and A2E are unlikely to cause photoreceptor degeneration in 5-week-old $i r b p^{-/-}$mice.

What is the cause of reduced cone function in irbp $p^{-1-}$ mice? The distal 10\% of rod OS are shed each day and phagocytosed by the overlying RPE (Young and Bok, 1969). Shedding of distal cone OS has also been observed (Hogan et al., 1974). Shedding of OS occurs in both dark- and cyclic-light-reared mice (LaVail, 1976). To keep up with this diurnal shedding, photoreceptors must daily synthesize $\sim 10 \%$ of the total opsin content, and the RPE must synthesize a corresponding quantity of 11-cis-RAL chromophore. The visual cycle is strongly stimulated by light (Radu et al., 2008a), hence the supply of 11-cis-RAL for newly synthesized rhodopsin and cone opsins is limited in the dark. Apo-opsin and 11-cis-RAL recombine to form a new visual pigment. The reversibility of this reaction is much higher with the cone opsins versus rhodopsin (Defoe and Bok, 1983; Kefalov et al., 2005). To illustrate this reversibility, dark-adapted salamander red cones contain 10\% apo-opsin and free 11-cisRAL (Kefalov et al., 2005). Rods therefore have a tendency to "steal" 11-cis-RAL chromophore from cones in the dark. Cone opsins require 11-cis-RAL as a chaperone for their correct targeting to the OS (Rohrer et al., 2005; Zhang et al., 2008). Therefore, a possible mechanism for the greater cone dysfunction in irbp $p^{-/-}$ mice is mistrafficking of cone opsins due to inadequate delivery of 11-cis-RAL. The rescue of cone-opsin mistrafficking and improved cone ERG response after delivery of excess 9-cis-RAL chromophore (Fig. 6E), and the reduced cone ERG response (Fig. 9) and cone-opsin mRNA levels (Fig. 8A) in dark-reared $\mathrm{irbp}^{-/-}$mice support this proposed mechanism.

Cone-dominant chickens and ground squirrels may possess an alternate visual cycle in Müller cells that supplies chromophore-precursor directly to cones (Mata et al., 2002, 


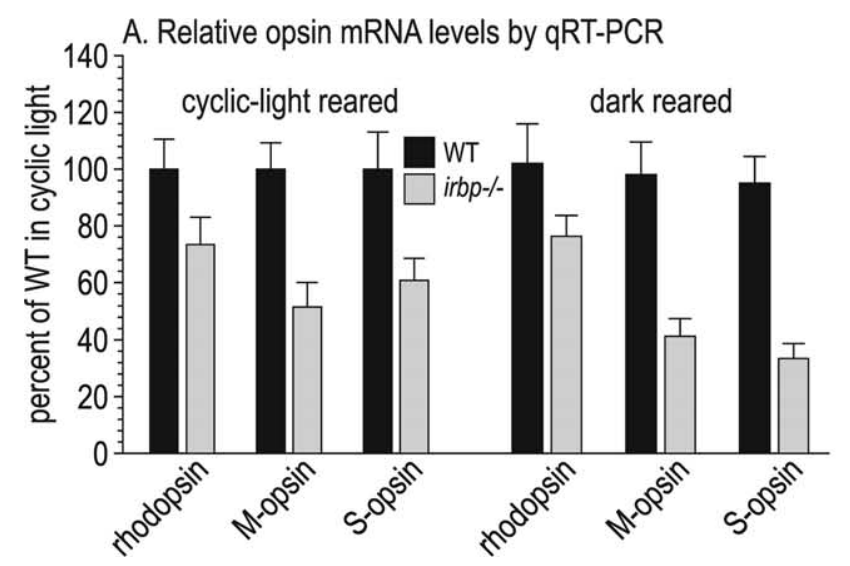

\section{B. Immunoblots of Opsins and Rpe65}

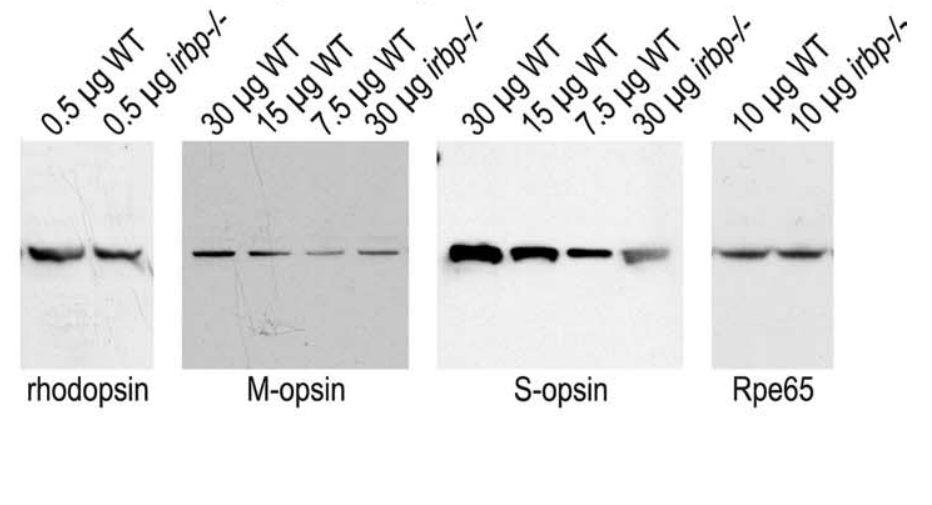

Figure 8. Quantitation of opsin mRNA's and proteins in wild-type and irbp ${ }^{-1-}$ mice. $A$, Relative opsin mRNA levels by qRT-PCR. Opsin mRNA levels were normalized to 185 rRNA, and the $\Delta C t$ values for each $\mathrm{mRNA}$ in irbp $^{-1-}$ retinas is shown as the percentage of the level in wild-type (WT) cyclic-light-reared mice. $\boldsymbol{B}$, Immunoblots of opsins and Rpe65. Immunoblots were performed on the indicated amounts of total protein in retina (rhodopsin, M-opsin, and S-opsin) or RPE (Rpe65) homogenates. The relative amounts of M-opsin and S-opsin in irbp ${ }^{-1-}$ retinas can be estimated by comparing the immunoblot signal strengths in lanes containing different amounts of WT retina homogenate to the immunoblot signals in lanes containing $30 \mu \mathrm{g}$ of irbp ${ }^{-/-}$retina homogenate.

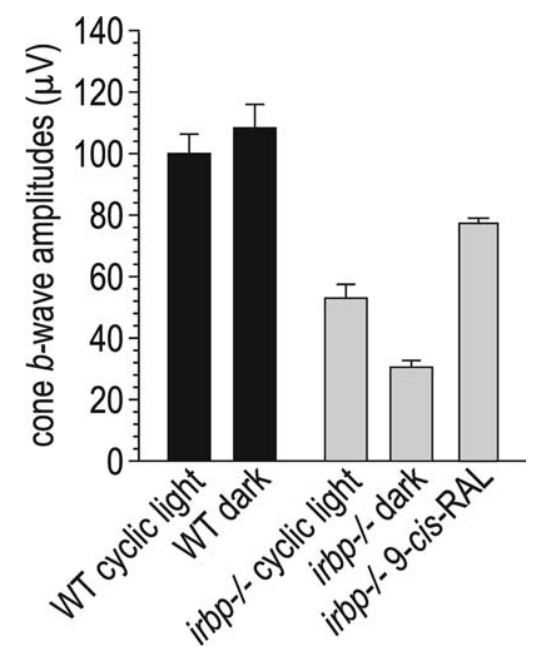

Figure 9. Cone ERG responses in dark-reared and 9-cis-RAL-supplemented mice. Cone $b$-wave responses are shown for wild-type (WT) and irbp ${ }^{-1-}$ mice raised in cyclic light or total darkness. Cone $b$-wave responses are also shown for 9-cis-RAL-supplemented irbp ${ }^{-/-}$mice raised under cyclic light. Note the reduced cone $b$-wave amplitude in irbp ${ }^{-1-}$ mice raised in darkness, and the improved $b$-wave amplitude in cyclic light-reared irbp ${ }^{-1-}$ mice treated with 9-cis-RAL.

2005). If present, this alternate pathway should protect cones from competition with rods for 11-cis-RAL chromophore. However, the catalytic activities that define this pathway were undetectable in mouse retinas (Mata et al., 2002). Thus, cones in the rod-dominant mouse retina are vulnerable to restrictions in chromophore supply.

In summary, we have shown that IRBP functions in vivo to accelerate transfer of all-trans-ROL from bleached photoreceptors to the RPE, and 11-cis-RAL from the RPE to photoreceptors. In the absence of IRBP, rods and cone degenerate at approximately equal rates. While the loss of rod function by ERG analysis is commensurate with the degree of photoreceptor degeneration, cone function is disproportionately reduced in $i r b p^{-/-}$mice. Reduced cone function may be mediated by mistrafficking of cone opsins due to the reduced availability of 11-cis-RAL chromophore. Cone degeneration is probably not caused by the elevated photobleach products observed in 5-week-old irbp ${ }^{-/-}$ mice, although these products may play a role in older mice. Our results do not speak directly to the mechanism of rod and cone degeneration in $\mathrm{irbp}^{-/-}$mice. One possibility is that beyond its role in retinoid translocation, IRBP has a trophic effect on rod and cone survival.

\section{References}

Carlson A, Bok D (1992) Promotion of the release of 11-cis-retinal from cultured retinal pigment epithelium by interphotoreceptor retinoidbinding protein. Biochemistry 31:9056-9062.

Carter-Dawson L, Alvarez RA, Fong SL, Liou GI, Sperling HG, Bridges CD (1986) Rhodopsin, 11-cis vitamin A, and interstitial retinol-binding protein (IRBP) during retinal development in normal and rd mutant mice. Dev Biol 116:431-438.

Carter-Dawson LD, LaVail MM (1979) Rods and cones in the mouse retina. I. Structural analysis using light and electron microscopy. J Comp Neurol 188:245-262.

Danciger M, Matthes MT, Yasamura D, Akhmedov NB, Rickabaugh T, Gentleman S, Redmond TM, La Vail MM, Farber DB (2000) A QTL on distal chromosome 3 that influences the severity of light-induced damage to mouse photoreceptors. Mamm Genome 11:422-427.

Defoe DM, Bok D (1983) Rhodopsin chromophore exchanges among opsin molecules in the dark. Invest Ophthalmol Vis Sci 24:1211-1226.

Edwards RB, Adler AJ (2000) IRBP enhances removal of 11- cis -retinaldehyde from isolated RPE membranes. Exp Eye Res 70:235-245.

Hogan MJ, Irmgard W, Steinberg RH (1974) Phagocytosis by pigment epithelium of human retinal cones. Nature 252:305-307.

Hollyfield JG, Fliesler SJ, Rayborn ME, Fong SL, Landers RA, Bridges CD (1985) Synthesis and secretion of interstitial retinol-binding protein by the human retina. Invest Ophthalmol Vis Sci 26:58-67.

Jimeno D, Feiner L, Lillo C, Teofilo K, Goldstein LS, Pierce EA, Williams DS (2006) Analysis of kinesin-2 function in photoreceptor cells using synchronous Cre-loxP knockout of Kif3a with RHO-Cre. Invest Ophthalmol Vis Sci 47:5039-5046.

Johnson LV, Hageman GS (1987) Enzymatic characterization of peanut agglutinin-binding components in the retinal interphotoreceptor matrix. Exp Eye Res 44:553-565.

Kefalov VJ, Estevez ME, Kono M, Goletz PW, Crouch RK, Cornwall MC, Yau KW (2005) Breaking the covalent bond-a pigment property that contributes to desensitization in cones. Neuron 46:879-890.

LaVail MM (1976) Rod outer segment disk shedding in rat retina: relationship to cyclic lighting. Science 194:1071-1074.

Liou GI, Bridges CD, Fong SL, Alvarez RA, Gonzalez-Fernandez F (1982) Vitamin A transport between retina and pigment epithelium-an interstitial protein carrying endogenous retinol (interstitial retinol-binding protein). Vision Res 22:1457-1467.

Liou GI, Wang M, Matragoon S (1994) Precocious IRBP gene expression during mouse development. Invest Ophthalmol Vis Sci 35:1083-1088.

Liou GI, Fei Y, Peachey NS, Matragoon S, Wei S, Blaner WS, Wang Y, Liu C, Gottesman ME, Ripps H (1998) Early onset photoreceptor abnormali- 
ties induced by targeted disruption of the interphotoreceptor retinoidbinding protein gene. J Neurosci 18:4511-4520.

MacKenzie D, Arendt A, Hargrave P, McDowell JH, Molday RS (1984) Localization of binding sites for carboxyl terminal specific anti-rhodopsin monoclonal antibodies using synthetic peptides. Biochemistry 23:6544-6549.

Maeda A, Maeda T, Imanishi Y, Kuksa V, Alekseev A, Bronson JD, Zhang H, Zhu L, Sun W, Saperstein DA, Rieke F, Baehr W, Palczewski K (2005) Role of photoreceptor-specific retinol dehydrogenase in the retinoid cycle in vivo. J Biol Chem 280:18822-18832.

Mata NL, Weng J, Travis GH (2000) Biosynthesis of a major lipofuscin fluorophore in mice and humans with $A B C R$-mediated retinal and macular degeneration. Proc Natl Acad Sci U S A 97:7154-7159.

Mata NL, Radu RA, Clemmons RC, Travis GH (2002) Isomerization and oxidation of vitamin a in cone-dominant retinas. A novel pathway for visual-pigment regeneration in daylight. Neuron 36:69-80.

Mata NL, Moghrabi WN, Lee JS, Bui TV, Radu RA, Horwitz J, Travis GH (2004) Rpe65 is a retinyl ester binding protein that presents insoluble substrate to the isomerase in retinal pigment epithelial cells. J Biol Chem 279:635-643.

Mata NL, Ruiz A, Radu RA, Bui TV, Travis GH (2005) Chicken retinas contain a retinoid isomerase activity that catalyzes the direct conversion of all-trans-retinol to 11-cis-retinol. Biochemistry 44:11715-11721.

Mavlyutov TA, Cai Y, Ferreira PA (2002) Identification of RanBP2- and kinesin-mediated transport pathways with restricted neuronal and subcellular localization. Traffic 3:630-640.

Palczewski K, Van Hooser JP, Garwin GG, Chen J, Liou GI, Saari JC (1999) Kinetics of visual pigment regeneration in excised mouse eyes and in mice with a targeted disruption of the gene encoding interphotoreceptor retinoid-binding protein or arrestin. Biochemistry 38:12012-12019.

Pepperberg DR, Brown PK, Lurie M, Dowling JE (1978) Visual pigment and photoreceptor sensitivity in the isolated skate retina. J Gen Physiol 71:369-396.

Qtaishat NM, Wiggert B, Pepperberg DR (2005) Interphotoreceptor retinoid-binding protein (IRBP) promotes the release of all-trans retinol from the isolated retina following rhodopsin bleaching illumination. Exp Eye Res 81:455-463.

Radu RA, Hu J, Peng J, Bok D, Mata NL, Travis GH (2008a) Retinal pigment epithelium-retinal G protein receptor-opsin mediates light-dependent translocation of all-trans-retinyl esters for synthesis of visual chromophore in retinal pigment epithelial cells. J Biol Chem 283:19730-19738.

Radu RA, Yuan Q, Hu J, Peng JH, Lloyd M, Nusinowitz S, Bok D, Travis GH (2008b) Accelerated accumulation of lipofuscin pigments in the RPE of a mouse model for ABCA4-mediated retinal dystrophies following vitamin A supplementation. Invest Ophthalmol Vis Sci 49:3821-3829.
Redmond TM, Wiggert B, Robey FA, Nguyen NY, Lewis MS, Lee L, Chader GJ (1985) Isolation and characterization of monkey interphotoreceptor retinoid-binding protein, a unique extracellular matrix component of the retina. Biochemistry 24:787-793.

Redmond TM, Weber CH, Poliakov E, Yu S, Gentleman S (2007) Effect of Leu/Met variation at residue 450 on isomerase activity and protein expression of RPE65 and its modulation by variation at other residues. Mol Vis 13:1813-1821.

Reinboth JJ, Gautschi K, Munz K, Eldred GE, Remé CE (1997) Lipofuscin in the retina: quantitative assay for an unprecedented autofluorescent compound (pyridinium bis-retinoid, A2-E) of ocular age pigment. Experimental Eye Research 65:639-643.

Ripps H, Peachey NS, Xu X, Nozell SE, Smith SB, Liou GI (2000) The rhodopsin cycle is preserved in IRBP "knockout" mice despite abnormalities in retinal structure and function. Vis Neurosci 17:97-105.

Rohrer B, Lohr HR, Humphries P, Redmond TM, Seeliger MW, Crouch RK (2005) Cone opsin mislocalization in Rpe65-/- mice: a defect that can be corrected by 11-cis retinal. Invest Ophthalmol Vis Sci 46:3876-3882.

Sakai N, Decatur J, Nakanishi K, Eldred GE (1996) Ocular age pigment "A2-E": an unprecedented pyridinium bisretinoid. J Am Chem Soc 118:1559-1560.

Travis GH, Golczak M, Moise AR, Palczewski K (2007) Diseases caused by defects in the visual cycle: retinoids as potential therapeutic agents. Annu Rev Pharmacol Toxicol 47:469-512.

Van Hooser JP, Liang Y, Maeda T, Kuksa V, Jang GF, He YG, Rieke F, Fong HK, Detwiler PB, Palczewski K (2002) Recovery of visual functions in a mouse model of Leber congenital amaurosis. J Biol Chem 277:19173-19182.

Weng J, Mata NL, Azarian SM, Tzekov RT, Birch DG, Travis GH (1999) Insights into the function of Rim protein in photoreceptors and etiology of Stargardt's disease from the phenotype in abcr knockout mice. Cell 98:13-23.

Wenzel A, Reme CE, Williams TP, Hafezi F, Grimm C (2001) The Rpe65 Leu450Met variation increases retinal resistance against light-induced degeneration by slowing rhodopsin regeneration. J Neurosci 21:53-58.

Wu Q, Blakeley LR, Cornwall MC, Crouch RK, Wiggert BN, Koutalos Y (2007) Interphotoreceptor retinoid-binding protein is the physiologically relevant carrier that removes retinol from rod photoreceptor outer segments. Biochemistry 46:8669-8679.

Young RW, Bok D (1969) Participation of the retinal pigment epithelium in the rod outer segment renewal process. J Cell Biol 42:392-403.

Zhang H, Fan J, Li S, Karan S, Rohrer B, Palczewski K, Frederick JM, Crouch RK, Baehr W (2008) Trafficking of membrane-associated proteins to cone photoreceptor outer segments requires the chromophore 11-cisretinal. J Neurosci 28:4008-4014. 